\title{
KML001 and doxercalciferol induce synergistic antileukemic effect in acute lymphoid leukemia cells
}

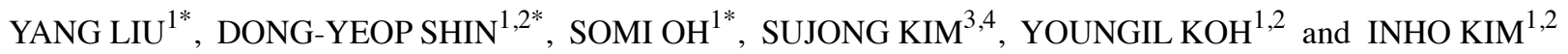 \\ ${ }^{1}$ Cancer Research Institute, Seoul National University College of Medicine; ${ }^{2}$ Division of Hematology \\ and Medical Oncology, Department of Internal Medicine, Seoul National University Hospital, \\ Seoul National University College of Medicine; ${ }^{3}$ Pharmaceutical Division, Komipharm International Co., Ltd.; \\ ${ }^{4}$ Graduate School of Biomedical Science and Engineering, Hanyang University, Seoul, Republic of Korea
}

Received December 19, 2016; Accepted May 12, 2017

DOI: $10.3892 /$ or.2017.5688

\begin{abstract}
KML001 ( $\mathrm{NaAsO}_{2}$, sodium metaarsenite, KOMINOX), a kind of arsenic compound, that has shown promising efficacy in non-Hodgkin's lymphoma (NHL) both in vitro and in vivo. In our study, the antileukemic effect of KML001 on acute lymphoid leukemia (ALL) and its mechanism of action were investigated. The results showed that KML001 inhibited cell proliferation in two types of ALL cell lines, CCRF-CEM and Molt-4. Exposure of ALL cells to KML001 induced apoptosis in a time-dependent manner. KML001 caused cell cycle arrest at G2/M phase instead of G0/G1 phase shown in other leukemia cells. In addition, we also tested the possibility of synergy of KML001 with doxercalciferol, a vitamin D2 derivative. Also, we found that a combination of KML001 with doxercalciferol showed a synergistic effect on ALL cell lines and this could be due to its different mechanism of action. Overall, our findings demonstrated KML001 could be a promising antileukemic agent especially when it is combined with doxercalciferol in ALL treatment.
\end{abstract}

\section{Introduction}

Acute lymphocytic leukemia (ALL), also called acute lymphoblastic leukemia, is a kind of lymphoid neoplasm. Lymphoid neoplasms have been divided into two major categories: neoplasms derived from B- and T-lineage lymphoid precursors and those derived from mature $\mathrm{B}$, T or NK cells in recent $\mathrm{WHO}$ classification (1). Also, ALL belongs to the first group which is B/T-precursor-stage lymphoid cell malignancies that block

Correspondence to: Dr Inho Kim, Division of Hematology and Medical Oncology, Department of Internal Medicine, Seoul National University Hospital, Seoul National University College of Medicine, 101 Daehagro, Chongno-Gu, Seoul 110-744, Republic of Korea

E-mail: ihkimmd@snu.ac.kr

*Contributed equally

Key words: KML001, doxercalciferol, acute lymphoid leukemia, synergy, CCEF-CEM, Molt-4 lymphoid differentiation and drive aberrant cell proliferation and survival. In addition, ALL is the most common leukemia in pediatrics, among which there are $\leq 80 \%$ of leukemia in this group and $20 \%$ of leukemia in adults (2). With the developments in theoretical knowledge and techniques, novel treatments in increasing number such as chemotherapy, steroids, radiation therapy and intensive combined treatments have been adopted for ALL treatment. Nevertheless, relapse among ALL patients is still the leading problem causing children's death. Despite the high cure rate in children with ALL, patients accounting for $10-20 \%$ are forecasted to relapse and outcomes of salvage therapy have been disappointing and only one-third of children survive long-term after recurrence of disease (3). In addition, the outcomes of adults with ALL are usually markedly worse than those of pediatric ones. Therefore, novel methods and effective drugs are urgently needed.

Arsenic is known as one of the toxic metalloids and its oxidized form, arsenic trioxide $\left(\mathrm{As}_{2} \mathrm{O}_{3}\right)$ has been successfully used as a medicine for patients with acute promyelocytic leukemia (APL) via intravenous injection. However, the anticancer effect of arsenic trioxide has not been proven in solid tumors or other hematologic malignancies (4). KML001 $\left(\mathrm{NaAsO}_{2}\right.$, sodium metaarsenite, KOMINOX), a sodium salt of arsenous acid, is water-soluble, therefore, orally bioavailable, trivalent arsenical compound. KML001 has shown a potent antitumor effect on various human cancers, including solid tumors such as prostate cancer, ovarian cancer and hematologic malignancy like acute myeloid leukemia (AML) (5-7). In addition, its half maximal inhibitory concentration $\left(\mathrm{IC}_{50}\right)$ has been found much lower than arsenic trioxide in various NHL cell lines, which may make it more suitable for clinical applications (8)

Based on epidemiological research $(9,10)$ and in vitro studies (11-13), vitamin D derivatives (VDDs) have been considered as a promising anticancer drug. As one of the most typical VDDs, 1, 25-dihydroxyvitamin D3 is known to control cell proliferation and differentiation as well as calcium related actions in leukemia cells (14-16). However, the side effect of hypercalcemia has limited its clinical application in hematologic malignancies. Doxercalciferol, a low calcemic vitamin D2 derivative with similar effect as 1,25-dihydroxyvitamin D3, can be safely given to patients and was investigated 
A

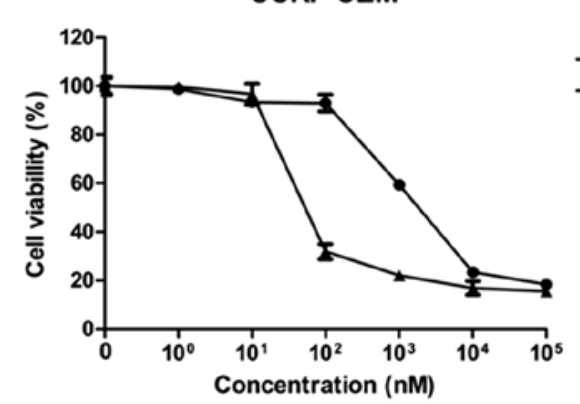

B

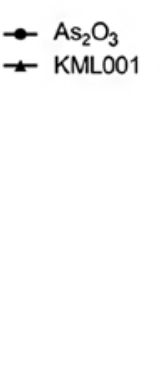

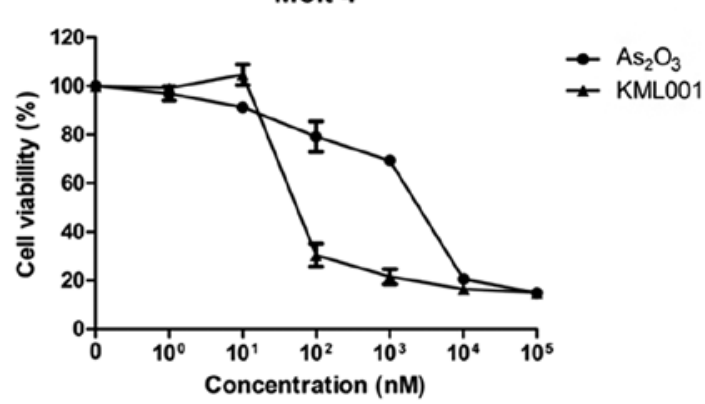

Figure 1. The superiority of KML001 compared to arsenite trioxide. CCRF-CEM cells and Molt-4 cells were treated with KML001 or arsenite trioxide at a variety of concentrations $\left(0,10^{0}, 10^{1}, 10^{2}, 10^{3}, 10^{4}\right.$ and $\left.10^{5} \mathrm{nM}\right)(\mathrm{A}$ and $\mathrm{B})$, the data are presented as the mean values from three separate experiments \pm SD.

in phase II studies of the myelodysplastic syndrome (17) and androgen-independent prostate cancer (18).

In this study, the antileukemic effect of KML001 on ALL was investigated, which was focused on apoptosis and cell cycle. In addition, the combination effect of KML001 with doxercalciferol was studied. We provided evidence of synergistic effect of KML001 and doxercalciferol in ALL cell lines and possible explanations of this synergy.

\section{Materials and methods}

Cells and cell culture. Human acute lymphoid leukemia cell line CCRF-CEM and Molt-4 were kindly presented by Dr Y.Y. Lee (Hanyang University, Seoul, Korea). The cells were cultured in tissue flasks or plates in RPMI-1640 medium supplemented with $10 \%$ fetal bovine serum (Gibco-BRL, Gaithersburg, MD, USA), $100 \mathrm{U} / \mathrm{ml}$ penicillin, $100 \mu \mathrm{g} / \mathrm{ml}$ streptomycin and incubated at $37^{\circ} \mathrm{C}$ in a humidified atmosphere with $5 \% \mathrm{CO}_{2}$.

Chemicals and antibodies. KML001 was obtained from Komipharm International (Siheung-Si, Gyeonggi-Do, Korea). $\mathrm{As}_{2} \mathrm{O}_{3}$ was purchased from Sigma-Aldrich (St. Louis, MO, USA). Doxercalciferol was purchased from Selleck Chemicals (Houston, TX, USA). Antibodies of Cdk1, p-Cdk1, cyclin B, p-p53, p-p21, Bcl-2, Bax, Bcl-xL were from Abcam (Cambridge, UK).

Growth inhibition assay. Cell viability was determined by Cell Counting Kit-8 (CCK-8, Dojindo Molecular Technologies, Gaithersburg, MD, USA). Cells $\left(5 \times 10^{3}\right.$ cells/well) were seeded in 96-well microtiter plates (Falcon) and then incubated at $37^{\circ} \mathrm{C}$ for $48 \mathrm{~h}$. After adding $10 \mu \mathrm{l}$ of the CCK-8 solution to each well of the plate, the plate was incubated for $\geq 1 \mathrm{~h}$ in the incubator. Finally, absorbance at $450 \mathrm{~nm}$ was measured by Multiskan Spectrum microplate reader (Thermo Labsystems, USA).

Western blot analysis. Cells were lysed with lysis buffer [25 mM Tris-HCl (pH 7.6), $150 \mathrm{mM} \mathrm{NaCl,} \mathrm{1 \%} \mathrm{NP-40,}$ $1 \%$ sodium deoxycholate, $0.1 \%$ SDS with Halt ${ }^{\mathrm{TM}}$ Protease, Phosphatase Inhibitor Cocktail and Benzonase ${ }^{\circledR}$ Nuclease] on ice for $20 \mathrm{~min}$. Briefly, protein samples were resolved in SDS-polyacrylamide gel, transferred to polyvinylidene difluoride (PVDF) membranes (Millipore, Billerica, MA, USA), and then probed with antibodies overnight. Finally, the blots were developed using the Pierce ${ }^{\mathrm{TM}}$ ECL Western Blotting Substrate (Thermo Fisher Scientific, USA).

Cell cycle distribution. Cells were fixed with $66 \%$ ethanol for $>2 \mathrm{~h}$ at $4{ }^{\circ} \mathrm{C}$ and then stained with $50 \mu \mathrm{g} / \mathrm{ml}$ of propidium iodide (PI) containing $550 \mathrm{U} / \mathrm{ml}$ of RNaseA (ab139418 PI Flow Cytometry kit for cell cycle analysis (Abcam, MA, USA). The DNA content of the cells was gated and analyzed using a FACSCanto II (Becton-Dickinson, San Jose, CA, USA) equipped with an FACSDiva software 8.0.1 (Becton-Dickinson).

Evaluation of apoptosis. Apoptosis was evaluated by FITC Annexin $\mathrm{V}$ apoptosis detection kit according to the manufacturer's instructions. Cells were washed twice with cold PBS, then resuspended in the $1 \mathrm{X}$ binding buffer, containing $0.01 \mathrm{M}$ HEPES/NaOH, $0.14 \mathrm{M} \mathrm{NaCl}$ and $2.5 \mathrm{mM} \mathrm{CaCl}_{2}, \mathrm{pH}$ 7.4. Next, a total of $100 \mu \mathrm{l}$ of the mixtures was transferred to a $5-\mathrm{ml}$ culture tube and then incubated with $5 \mu$ l Annexin V-FITC and $5 \mu \mathrm{l}$ propidium iodide for $15 \mathrm{~min}$ at room temperature in the dark. Subsequently, $400 \mu \mathrm{l}$ of $1 \mathrm{X}$ binding buffer was added to each tube and then cells were immediately analyzed by flow cytometry. In analysis process, Annexin V-positive or PI-negative cells were considered as early apoptotic, both Annexin V and PI-positive cells were considered as late apoptotic, and Annexin V-negative but PI-positive cells were considered as necrotic.

Intracellular calcium analysis. Cells treated with KML001, doxercalciferol or medium (control) for $48 \mathrm{~h}$ were washed three times with the PBS and then incubated with $4 \mu \mathrm{M}$ Fluo-4 AM (Thermo Fisher Scientific) and 0.1\% Pluronic F-127 (Thermo Fisher Scientific) in PBS for $60 \mathrm{~min}$ at $37^{\circ} \mathrm{C}$. After removing the medium in time, each well was washed with PBS and $200 \mu 1$ PBS was used to cover all cells in the trough. Finally, we used laser confocal scanning microscopy (LCSM) to measure the fluorescence intensity (FI) of the cells at an excitation wavelength of $488 \mathrm{~nm}$.

Statistical analysis. The combined effects of KML001 and doxercalciferol were analyzed by CalcuSyn software (Biosoft Ferguson, MO, USA) using the Chou-Talalay method (19). The combination index $(\mathrm{CI})$ values of $<1,1$ and $>1$ represent synergy, additive effect, and antagonism, respectively. All experiments have been repeated at least 3 times. Statistical 
A

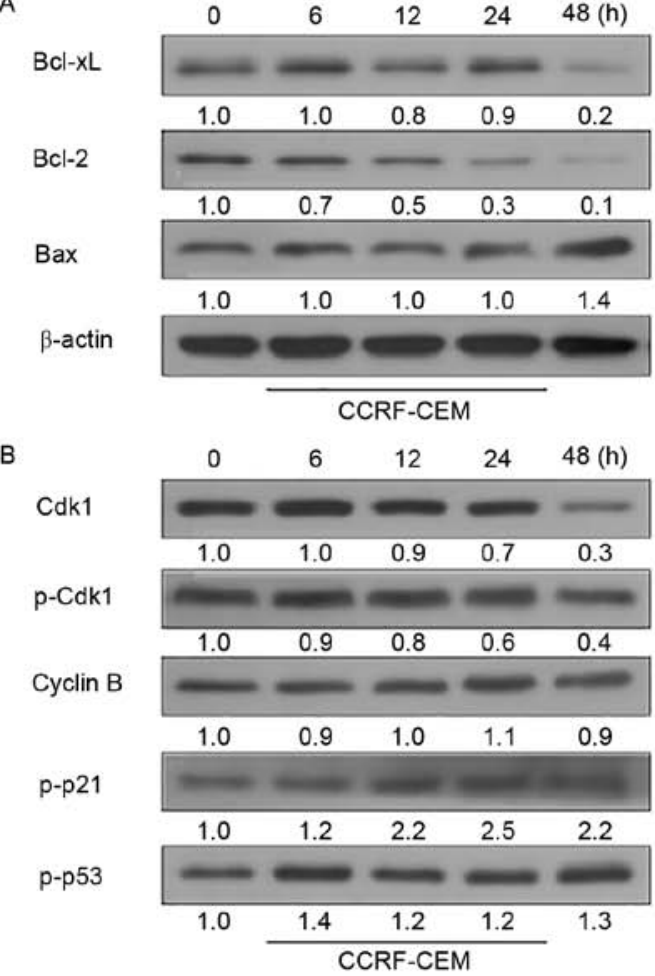

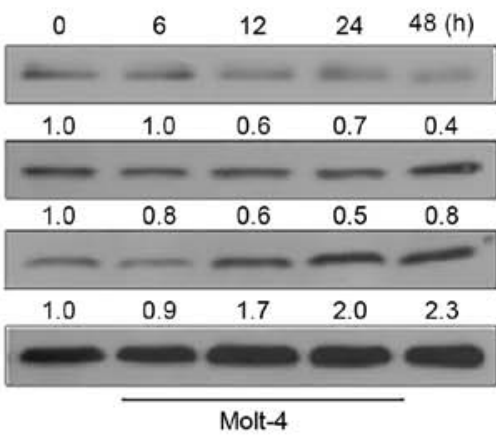
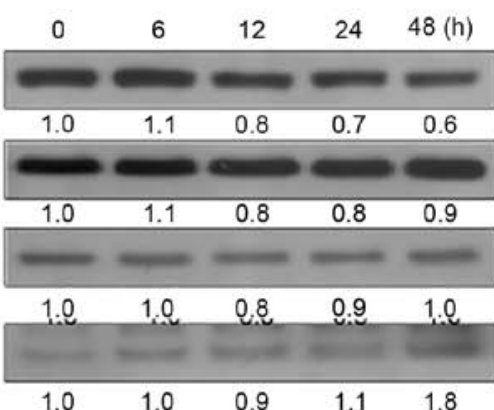

$\begin{array}{lllll}1.0 & 1.0 & 0.9 & 1.1 & 1.8\end{array}$

Molt-4

C
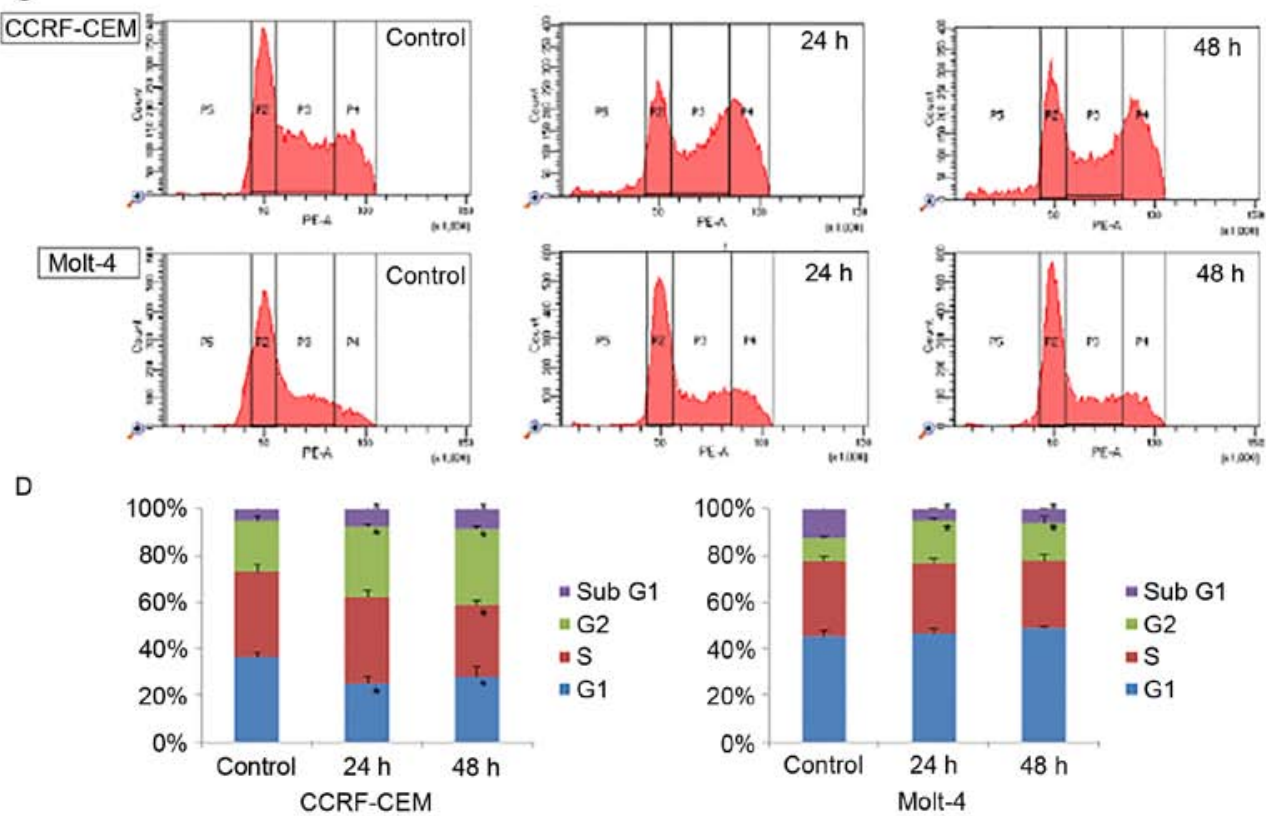

Figure 2. Antileukemic effects of KML001 on ALL cells. (A) Western blot analysis documents a time-dependent modulation of expression of Bcl-2 family members by KML001. Antibody to $\beta$-actin served as a loading control. (B) Western blot analysis of expression of cell cycle related protein: Cdk1, p-Cdk1, cyclin B, p-p21 and p-p53. ImageJ was used for quantify protein bands. (C) After treated with KML001 for 24 or 48 h or media as control, cells were stained with PI solution followed by analyses of cell cycle distribution using flow cytometry. (D) Quantitative analysis of results of C, the data are presented as the mean values from three separate experiments \pm SD.

significance was determined by using Student's t-test. P-value $<0.05$ was considered statistically significant.

\section{Results}

The superiority of KMLO01 compared with arsenite trioxide. The current experiments were initiated by treating CCRF-CEM and Molt-4 cells, in in vitro models of human ALL, for $48 \mathrm{~h}$ with two types of arsenic compounds, arsenic trioxide and KML001. Results showed that KML001 inhibited cell proliferation of the cell lines at a fairly lower concentration (>100-fold) than $\mathrm{As}_{2} \mathrm{O}_{3}$ (Fig. 1).

Antileukemic effects of KML001 on ALL cells. To further investigate the mechanism of action of KML001, western blot analysis was performed for apoptosis-related proteins in CCRF-CEM and Molt-4 cells (Fig. 2A). In both cell lines, decreased Bcl-xL and increased Bax were observed after 48-h 

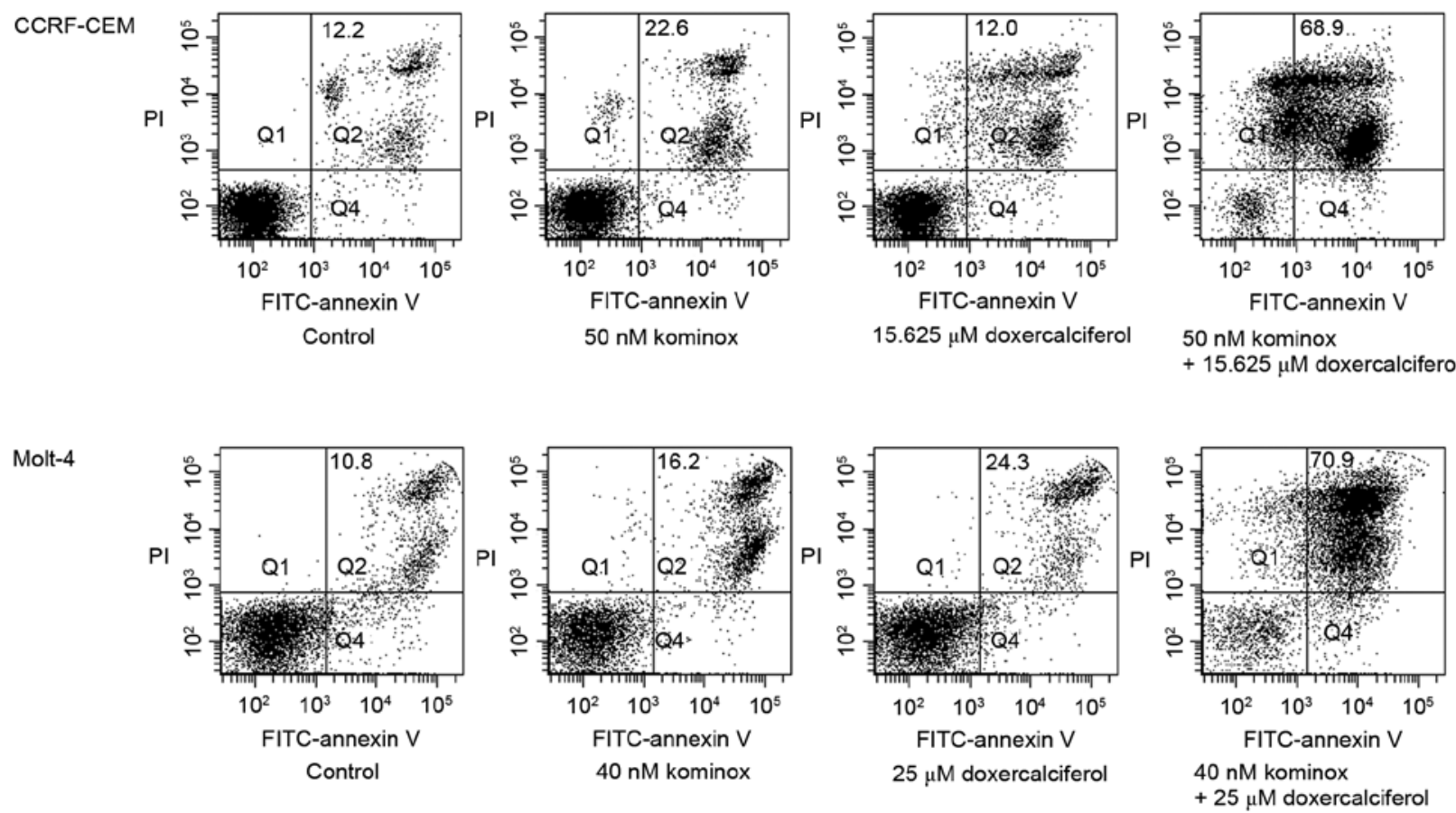

Figure 3. Synergistic antileukemic effect of KML001 combined with doxercalciferol. Flow cytometric analysis of Annexin V-FITC/PI-stained CCRF-CEM and Molt- 4 cells treated for $48 \mathrm{~h}$ with KML001 and doxercalciferol either alone or combination. A significant increase of apoptotic cells was observed in groups treated with the drug combination with respect to single treatments.

Table I. MTT assay for synergistic effect of KML001 and doxercalciferol.

\begin{tabular}{lcccc}
\hline Cell lines & $\begin{array}{c}\text { KML001 } \\
(\mathrm{nM})\end{array}$ & $\begin{array}{c}\text { Doxercalciferol } \\
(\mu \mathrm{M})\end{array}$ & $\begin{array}{c}\text { Fraction of } \\
\text { cell death }\end{array}$ & CI \\
\hline CCRF-CEM & 10 & 3.125 & 0.183 & 1.529 \\
& 20 & 6.25 & 0.367 & 1.242 \\
& 40 & 12.5 & 0.556 & 1.195 \\
& 50 & 15.625 & 0.723 & 0.741 \\
& 60 & 18.75 & 0.775 & 0.682 \\
& 80 & 25 & 0.801 & 0.786 \\
Molt-4 & 5 & 3.125 & 0.082 & 1.226 \\
& 10 & 6.25 & 0.107 & 1.906 \\
& 20 & 12.5 & 0.280 & 1.394 \\
& 40 & 25 & 0.683 & 0.675 \\
& 80 & 50 & 0.809 & 0.782 \\
& 160 & 100 & 0.777 & 1.824
\end{tabular}

CI, combination index.

treatment of KML001. Expression of anti-apoptotic protein Bcl-2 decreased markedly in CCRF-CEM cell line while its expression increased a little in the Molt-4 cell line.

Cdk1/cyclin B1 complex, the critical regulator of G2/M checkpoint, plays important roles in mitosis and mitotic catastrophe $(20,21)$. As shown in Fig. 2B, the expression of Cdk1 kept decreasing after treatment of KML001 while cyclin B1 expression did not show any change. Lack of Cdk1 may cause cell arrest at G2/M phase. To confirm this point, we conducted cell cycle analysis by propidium iodide staining of the treated cells followed by flow cytometry (Fig. 2C). As shown by the G2/M ratios in both cell lines (Fig. 2D), KML001 did induce cell cycle arrest both in CCRF-CEM and Molt-4 cells. Previous studies suggest that p53 and p21 were involved in both cell cycle arrest and cell apoptosis $(22,23)$. Here, we found $\mathrm{p} 53 / \mathrm{p} 21^{\mathrm{WAF} 1}$ pathway was involved in KML001-induced G2/M phase arrest. Fig. 2B indicates that p-p21 expression increased in a time-dependent manner in CCRF-CCEM and Molt-4 cells after KML001 treatment. In addition, increased p53 phosphorylation was observed in CCRF-CEM cells but not in Molt-4 cells which are p53-deficient.

Synergistic antileukemic effect of KMLO01 combined with doxercalciferol. We also investigated whether KML001 and doxercalciferol could cause synergistic effects in terms of reduced cell viability in ALL cell lines. CCRF-CEM and Molt-4 cell lines were incubated for $48 \mathrm{~h}$ with one drug alone or with a combination treatment of KML001 and doxercalciferol at a constant ratio of 1:312.5 or 1:625 (KML001:doxercalciferol). $\mathrm{CI}$ and cell viability were then calculated. As shown in Table I, in the two cell lines, the combined treatments were synergistic, as indicated by $\mathrm{CI}<1$.

To further evaluate its synergy, flow cytometry analysis was performed. Also, we observed a significant increase of late apoptotic cells (double-positive for Annexin V and PI) after combination treatment compared with single treatment of KML001 or doxercalciferol (Fig. 3).

Doxercalciferol induces cell arrest at G2/M phase. Western blot analysis and flow cytometry were performed to know whether doxercalciferol induces cell cycle arrest in ALL 
A

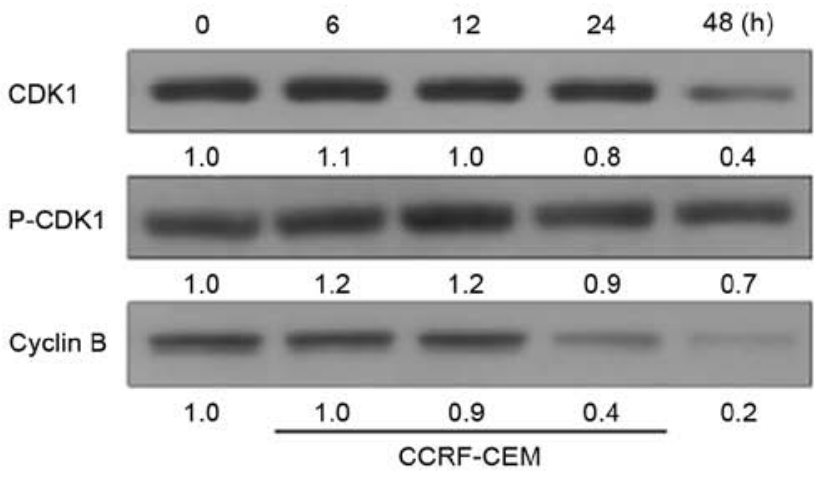

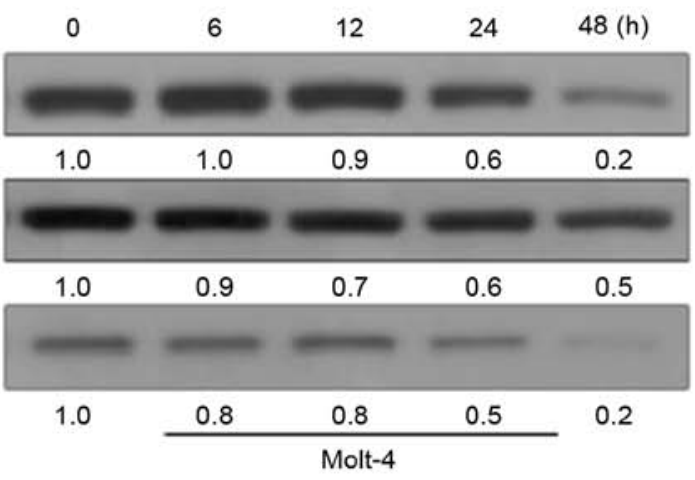
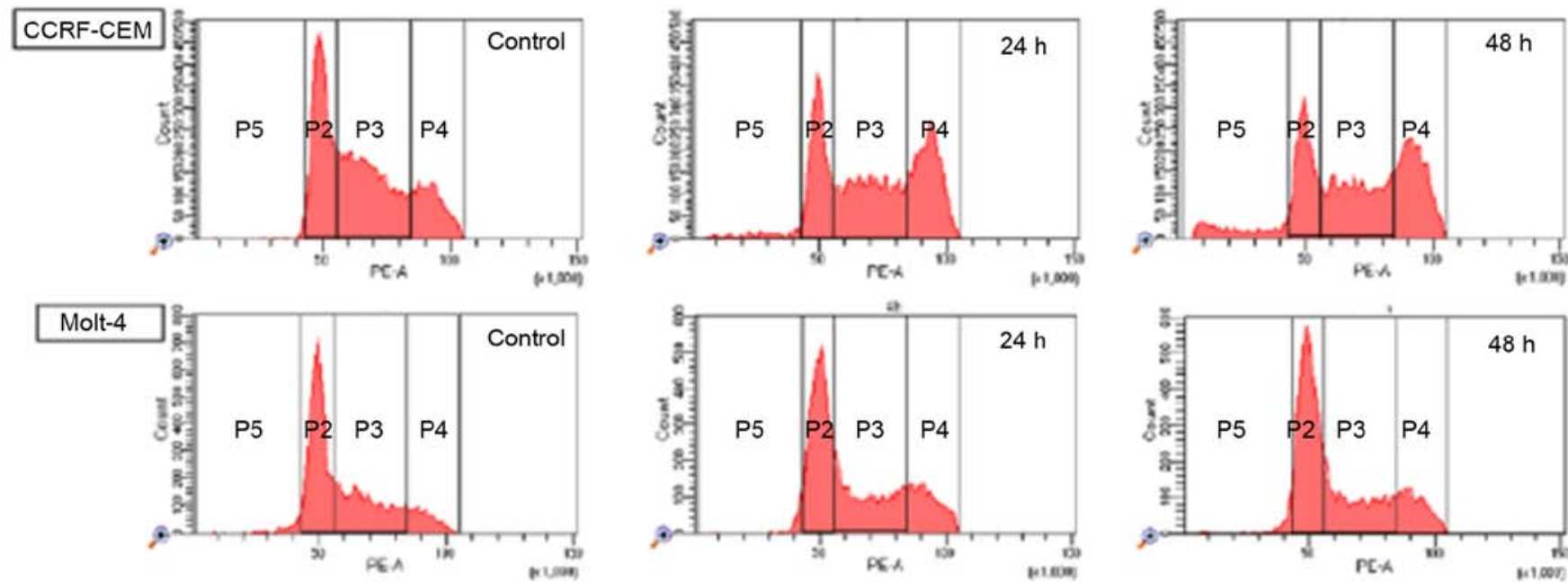

C
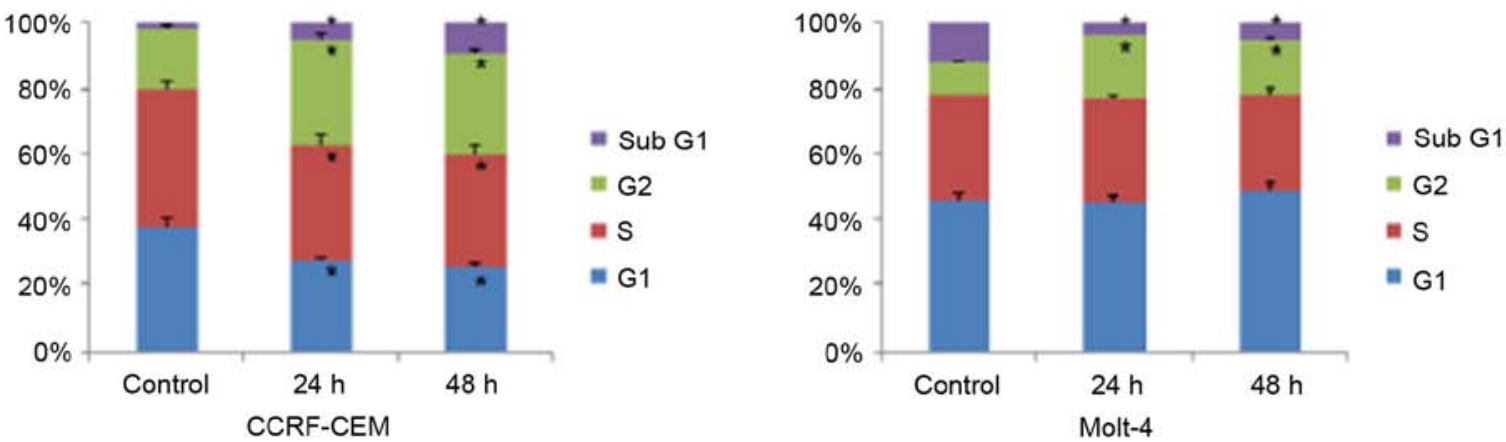

Figure 4. Doxercalciferol induces cell arrest at G2/M phase. (A) Western blot analysis of expression of cell cycle-related proteins: Cdk1, p-Cdk1, cyclin B ImageJ was used to quantify protein bands. (B) After treated with doxercalciferol for 24 or $48 \mathrm{~h}$ or media as control, cells were stained with PI solution followed by analyses of cell cycle distribution using flow cytometry. (C) Quantitative analysis of results of B, the data are presented as the mean values from three separate experiments $\pm \mathrm{SD}$.

cells. As shown in Fig. 4A, expression of Cdk1 and cyclin B decreased in a time-dependent manner after treatment, which indicates that doxercalciferol may also lead to G2/M phase arrest of these two cell lines. Flow cytometry analysis indicates that doxercalciferol was able to induce cell cycle arrest at G2/M phase in CCRF-CEM and Molt-4 cells (Fig. 4B and C).

Doxercalciferol induces cell apoptosis and cell arrest via different mechanism of action. To further identify mechanisms underlying this synergy, we also tried to understand mechanisms of action of doxercalciferol in ALL models in vitro. The pro-apoptotic protein Bax and anti-apoptotic protein $\mathrm{Bcl}-\mathrm{xL}$ did not change as we expected (Fig. 5A). Considering the late apoptotic cells observed in flow cytometry results, doxercalciferol may cause cell apoptosis without the involvement of Bcl-2 family pathway.

In addition, we tried to understand mechanisms of doxercalciferol-induced G2/M phase arrest by studying intracellular signaling pathway through western blot analyses. However, doxercalciferol neither induce p53 activation nor p21 activation in the two cell lines (Fig. 5B).

Finally, to investigate whether doxercalciferol-induced apoptosis is associated with $\mathrm{Ca}^{2+}$, the effect of doxercalciferol on intracellular calcium ion concentration in ALL cells was observed by using LSCM after staining with the fluorescent probe, Fluo-4/AM. As shown in Fig. 5C-L, the depth of the 

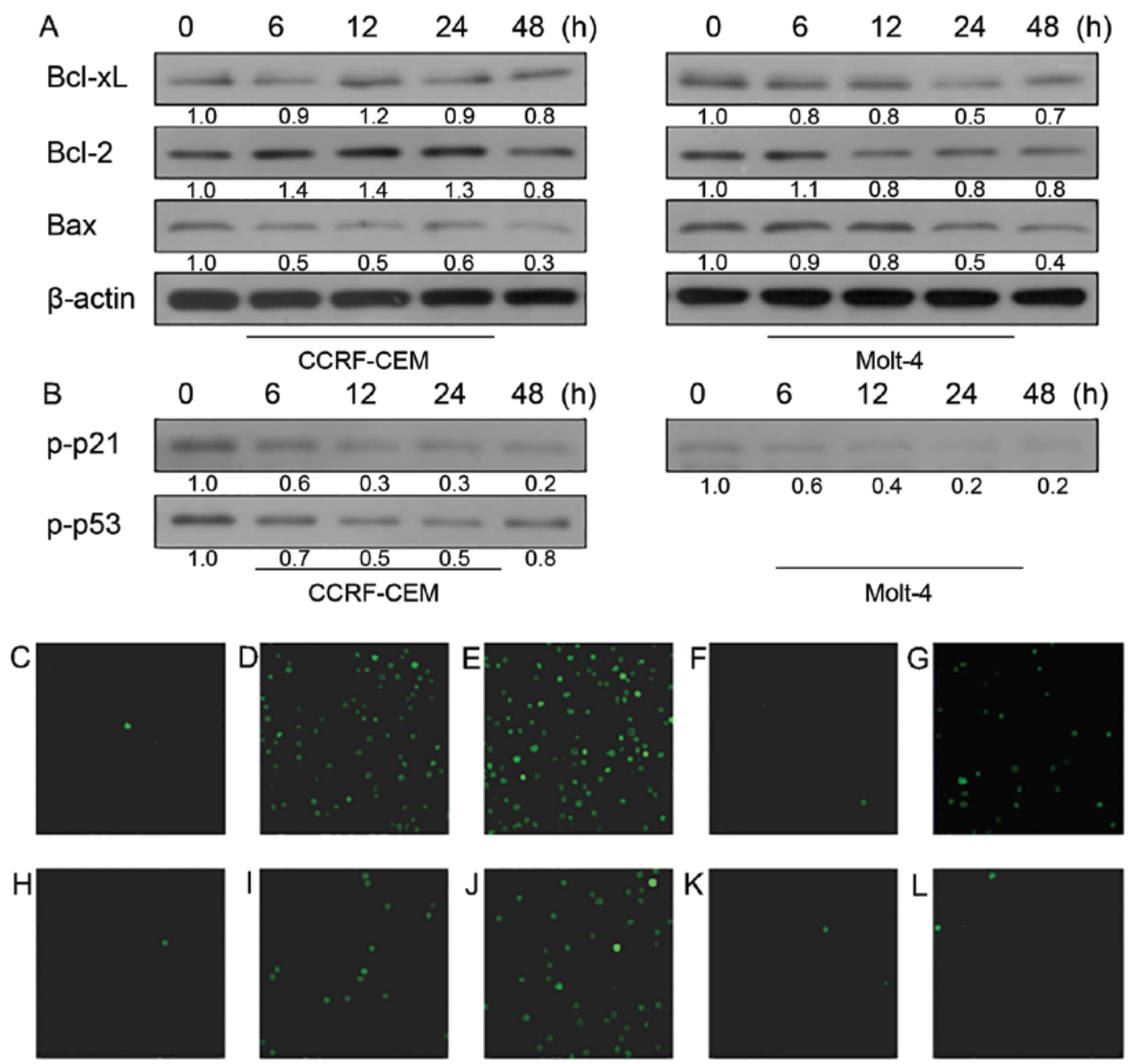

Figure 5. Mechanisms of action of doxercalciferol-induced cell cycle and apoptosis. (A and B) Western blot analysis of Bcl-2 family members, p21 and p53 expression after treating cells with doxercalciferol. ImageJ was used to quantify protein bands. Intracellular calcium accumulation occurred in CCRF-CEM and Molt-4 cells. Images (green) reveal $\left[\mathrm{Ca}^{2+}\right]_{\mathrm{i}}$ under a confocal microscope, with the depth of the color represents the fluorescence intensity (FI), which indirectly reflects $\left[\mathrm{Ca}^{2+}\right]_{\mathrm{i}} \cdot(\mathrm{C}$ and $\mathrm{H})$ Control for CCRF-CEM and Molt- 4 cell line respectively. (D and I) Cells treated with doxercalciferol for $24 \mathrm{~h}$ and (E and J) for $48 \mathrm{~h}$. (F and K) Cells treated with KML001 for $24 \mathrm{~h}$ and (G and L) for $48 \mathrm{~h}$.

green signal, which indirectly reflects intracellular $\mathrm{Ca}^{2+}$ concentration, increased as the time increased after treatment of doxercalciferol while there was relatively less change observed in groups treated with KML001.

\section{Discussion}

Acute lymphoblastic leukemia occurs when primitive or immature lymphoid cells grow uncontrollably, disturbing normal hematopoiesis. Until now, it is still one of the most aggressive hematologic malignancies. With the progress and availability of combination chemotherapy, radiotherapy or hematopoietic cell transplantation, the outcomes of ALL patients have improved markedly. However, there are still many who cannot survive after treatment due to problems such as relapse, drug resistance or side effects like toxicity. Here, we evaluated antileukemic activity of KML001, a kind of arsenic compound alone and KML001 combined with doxercalciferol in ALL cells.

Previous studies have demonstrated that antileukemia activity of KML001 is mainly due to its ability to induce apoptosis and cell cycle arrest via regulation of MAPK and
PI3K pathways or telomere shortening $(6,24)$. Also, our study showed that KML001 induced apoptosis both in CCRF-CEM and Molt- 4 cell lines. Gene expression of Bcl-xL, Bax, Bcl-2, members of Bcl-2 family, has been known to control the apoptotic machinery (25). KML001 increased expression of pro-apoptotic protein Bax, and suppressed the expression of anti-apoptotic protein $\mathrm{Bcl}-\mathrm{xl}$ in both cell lines.

$\mathrm{Cdk} 1 /$ cyclin B1 complex is one of the pivotal signaling molecules driving cell progression, which is involved in $\mathrm{G} 2 / \mathrm{M}$ checkpoint. Downregulation of Cdk1 or cyclin B1 expression may lead to cell cycle arrest at $\mathrm{G} 2 / \mathrm{M}$ phase. In our experiments, constant decreasing expression of Cdk1 in western blotting plus flow cytometry results identified that treatment with KML001 induced cell cycle arrest mainly at $\mathrm{G} 2 / \mathrm{M}$ phase rather than at G0/G1 phase which was shown in AML research (6). To investigate the specific mechanism of KML001-induced G2/M phase arrest, we checked the expression of p-p53 and p-p21 by western blot analyses. Results showed a constant increase of expression of p-p53 or p-p21 after treatment of KML001. The activation of $\mathrm{p} 21$ and $\mathrm{p} 53$, which are the main regulator of CDK1, might be precedent to the change of Cdk1 after KML001 treatment in CCRF-CEM and Molt-4 cells. 
In addition, KML001 may cause cell arrest and apoptosis in Molt-4 cells through non-p53 involved pathway since these cells are p53-deficient. This difference may be associated with the reality that Molt-4 cell line was created from a relapsed patient but CCRF-CEM cell line was not.

In order to overcome the possible resistance of KML001, we tried to evaluate the additional benefit of doxercalciferol in combination with KML001 in vitro models. As far as we know, this is the first study demonstrating the combination effect of KML001 with doxercalciferol against ALL cells. Also, in our results, the combinatorial treatment of KML001 with doxercalciferol showed a synergistic antileukemic activity in CCRF-CEM and Molt-4 cell lines, which suggests that the different mechanisms might work in ALL cells co-treated with KML001 and doxercalciferol.

Vitamin D and vitamin D analogs exert its anticancer effects mainly through anti-proliferation, pro-differentiation and pro-apoptotic effect (26). Unlike KML001 treatment, doxercalciferol treatment induced increment of intracellular calcium ion level. Furthermore, doxercalciferol induced apoptosis and G2/M phase cell cycle arrest but without the involvement of Bcl-2 family pathways or activation of p53 and p21.

Collectively, KML001 suppressed Cdk1 via p53 and p21 activation. These changes led to cell cycle arrest at $\mathrm{G} 2 / \mathrm{M}$ phase in ALL cells, and its apoptosis mechanisms also includes p53, p21 activation and other mechanisms such as telomere length shortening. However, doxercalciferol induced cell apoptosis and cell cycle arrest in a totally different way, which involves calcium related pathway but without activation of proteins $\mathrm{p} 53$, p21 or Bcl-2 family involved pathway. This study provided evidence that KML001 could be an effective anti-leukemic agent especially with doxercalciferol in ALL treatment in the terms of cell level. Its availability on clinical application, however, should be further investigated.

\section{Acknowledgements}

This study was supported by Seoul National University College of Medicine (800-20130310 and 800-20140171), Komipharm International Co., Ltd., Seoul, Korea and the Basic Science Research Program through the National Research Foundation of Korea (NRF) funded by the Ministry of Education (NRF-2016-0024046).

\section{References}

1. Swerdllow S, Campo E and Harris NL: WHO Classification of Tumours of Haematopoietic and Lymphoid Tissues. 4th edition. IARC Press, Lyon, 2008.

2. Zuckerman T and Rowe JM: Pathogenesis and prognostication in acute lymphoblastic leukemia. F1000Prime Rep 6: 59, 2014.

3. Raetz EA and Bhatla T: Where do we stand in the treatment of relapsed acute lymphoblastic leukemia? Hematology Am Soc Hematol Educ Program 2012: 129-136, 2012.

4. Litzow MR: Arsenic trioxide. Expert Opin Pharmacother 9: $1773-1785,2008$.

5. You D, Kim Y, Jang MJ, Lee C, Jeong IG, Cho YM, Hwang JJ, Hong JH, Ahn H and Kim CS: KML001 induces apoptosis and autophagic cell death in prostate cancer cells via oxidative stress pathway. PLoS One 10: e0137589, 2015

6. Yoon JS, Kim ES, Park BB, Choi JH, Won YW, Kim S and Lee YY: Anti-leukemic effect of sodium metaarsenite (KML001) in acute myeloid leukemia with breaking-down the resistance of cytosine arabinoside. Int J Oncol 46: 1953-1962, 2015.
7. Muenyi CS, Trivedi AP, Helm CW and States JC: Cisplatin plus sodium arsenite and hyperthermia induces pseudo-G1 associated apoptotic cell death in ovarian cancer cells. Toxicol Sci 139: 74-82, 2014.

8. Yoon JS, Hwang DW, Kim ES, Kim JS, Kim S, Chung HJ, Lee SK, Yi JH, Uhm J, Won YW, et al: Anti-tumoral effect of arsenic compound, sodium metaarsenite (KML001), in non-Hodgkin's lymphoma: An in vitro and in vivo study. Invest New Drugs 34: $1-14,2016$.

9. Grant WB and Garland CF: The association of solar ultraviolet B (UVB) with reducing risk of cancer: Multifactorial ecologic analysis of geographic variation in age-adjusted cancer mortality rates. Anticancer Res 26A: 2687-2699, 2006.

10. Giovannucci E, Liu Y, Rimm EB, Hollis BW, Fuchs CS, Stampfer MJ and Willett WC: Prospective study of predictors of vitamin D status and cancer incidence and mortality in men. J Natl Cancer Inst 98: 451-459, 2006.

11. Colston K, Colston MJ and Feldman D: 1,25-dihydroxyvitamin D3 and malignant melanoma: The presence of receptors and inhibition of cell growth in culture. Endocrinology 108: 1083-1086, 1981.

12. Miyaura C, Abe E, Kuribayashi T, Tanaka H, Konno K, Nishii Y and Suda T: 1 $\alpha, 25$-Dihydroxyvitamin D3 induces differentiation of human myeloid leukemia cells. Biochem Biophys Res Commun 102: 937-943, 1981.

13. Gardner JP, Zhang F, Uskokovic MR and Studzinski GP: Vitamin D analog 25-(OH)-16,23E-Diene-26,27-hexafluorovitamin D3 induces differentiation of HL60 cells with minimal effects on cellular calcium homeostasis. J Cell Biochem 63: 500-512, 1996.

14. McCarthy DM, San Miguel JF, Freake HC, Green PM, Zola H, Catovsky D and Goldman JM: 1,25-dihydroxyvitamin D3 inhibits proliferation of human promyelocytic leukaemia (HL60) cells and induces monocyte-macrophage differentiation in HL60 and normal human bone marrow cells. Leuk Res 7: 51-55, 1983.

15. Zhang Y, Zhang J and Studzinski GP: AKT pathway is activated by 1,25-dihydroxyvitamin D3 and participates in its anti-apoptotic effect and cell cycle control in differentiating HL60 cells. Cell Cycle 5: 447-451, 2006.

16. Sergeev IN: Calcium as a mediator of 1,25-dihydroxyvitamin D3-induced apoptosis. J Steroid Biochem Mol Biol 89-90: 419-425, 2004.

17. Petrich A, Kahl B, Bailey H, Kim K, Turman N and Juckett M: Phase II study of doxercalciferol for the treatment of myelodysplastic syndrome. Leuk Lymphoma 49: 57-61, 2008.

18. Liu G, Wilding G, Staab MJ, Horvath D, Miller K, Dresen A, Alberti D, Arzoomanian R, Chappell R and Bailey HH: Phase II study of $1 \alpha$-hydroxyvitamin $\mathrm{D}(2)$ in the treatment of advanced androgen-independent prostate cancer. Clin Cancer Res 9: 4077-4083, 2003.

19. Chou T-C and Talalay P: Quantitative analysis of dose-effect relationships: The combined effects of multiple drugs or enzyme inhibitors. Adv Enzyme Regul 22: 27-55, 1984.

20. Castedo M, Perfettini J-L, Roumier T, Andreau K, Medema R and Kroemer G: Cell death by mitotic catastrophe: A molecular definition. Oncogene 23: 2825-2837, 2004.

21. Castedo M, Perfettini J-L, Roumier T, Valent A, Raslova H, Yakushijin K, Horne D, Feunteun J, Lenoir G, Medema R, et al: Mitotic catastrophe constitutes a special case of apoptosis whose suppression entails aneuploidy. Oncogene 23: 4362-4370, 2004.

22. Abbas T and Dutta A: p21 in cancer: Intricate networks and multiple activities. Nat Rev Cancer 9: 400-414, 2009.

23. Taylor WR and Stark GR: Regulation of the G2/M transition by p53. Oncogene 20: 1803-1815, 2001.

24. Woo SR, Ham Y, Kang W, Yang H, Kim S, Jin J, Joo KM and Nam DH: KML001, a telomere-targeting drug, sensitizes glioblastoma cells to temozolomide chemotherapy and radiotherapy through DNA damage and apoptosis. BioMed Res Int 2014: 747415,2014

25. Gross A, McDonnell JM and Korsmeyer SJ: BCL-2 family members and the mitochondria in apoptosis. Genes Dev 13: 1899-1911, 1999.

26. Guyton KZ, Kensler TW and Posner GH: Cancer chemoprevention using natural vitamin D and synthetic analogs. Annu Rev Pharmacol Toxicol 41: 421-442, 2001. 